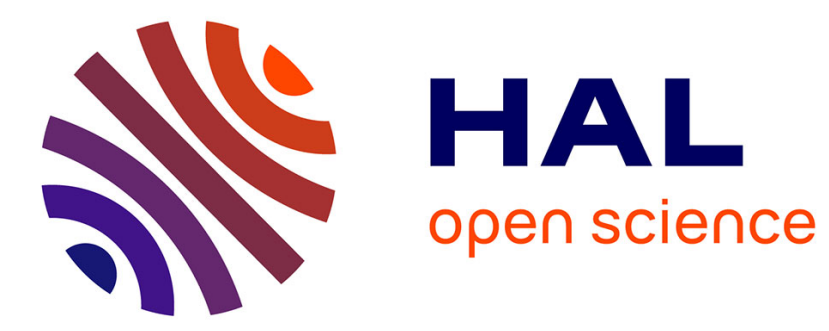

\title{
Effect of oxidation on spectral and integrated emissivity of Ti-6Al-4V alloy at high temperatures
}

Abdelmagid El Bakali, Rémi Gilblas, Thomas Pottier, Adrien Lieurey, Yannick Le Maoult

\section{To cite this version:}

Abdelmagid El Bakali, Rémi Gilblas, Thomas Pottier, Adrien Lieurey, Yannick Le Maoult. Effect of oxidation on spectral and integrated emissivity of Ti-6Al-4V alloy at high temperatures. Journal of Alloys and Compounds, 2021, 889, pp.1-11/161545. 10.1016/j.jallcom.2021.161545 . hal-03328838

\section{HAL Id: hal-03328838 \\ https://imt-mines-albi.hal.science/hal-03328838}

Submitted on 1 Sep 2021

HAL is a multi-disciplinary open access archive for the deposit and dissemination of scientific research documents, whether they are published or not. The documents may come from teaching and research institutions in France or abroad, or from public or private research centers.
L'archive ouverte pluridisciplinaire HAL, est destinée au dépôt et à la diffusion de documents scientifiques de niveau recherche, publiés ou non, émanant des établissements d'enseignement et de recherche français ou étrangers, des laboratoires publics ou privés. 


\title{
Effect of oxidation on spectral and integrated emissivity of Ti-6Al-4V alloy at high temperatures
}

\author{
A. El Bakali*, R. Gilblas, T. Pottier, A. Lieurey, Y. Le Maoult \\ Institut Clement Ader (ICA), Université de Toulouse, CNRS, Mines Albi, UPS, INSA, ISAE-SUPAERO, Campus Jarlard, 81013 Albi CT Cedex 09, France
}

\begin{abstract}
A B S T R A C T
Thermomechanical simulation is challenging for the optimization and virtual monitoring of high temperature shape processes, such as SuperPlastic Forming (SPF) of Titanium alloys alike Ti-6Al-4V (TA6V). Part of this challenge is the accurate and process-representative knowledge of emissivity, which controls radiative heat transfer during the process. In this paper, the characterization of TA6V emissivity, with regards to its oxidation stage, is performed within the $\left[600-1000{ }^{\circ} \mathrm{C}\right]$ thermal range. The main contribution of this work is the use of an in-house characterization bench, enabling the fast radiative heating of samples, and the control of oxide layers thicknesses ranging from $250 \mathrm{~nm}$ to $120 \mu \mathrm{m}$. An oxidation law is established thanks to post-mortem mass gain and oxide thicknesses measurement, and the various oxide phases are identified. Oxide thicknesses versus heating time were then calculated and implemented in the emissivity analysis. Two patterns are observed for oxide thickness versus temperature: below $900{ }^{\circ} \mathrm{C}$, emissivity values are quasi-continuously increasing with oxide thickness, exhibiting an oxide layer mainly composed by $\mathrm{TiO}_{2}$, above $900{ }^{\circ} \mathrm{C}$, emissivity values are also continuously increasing but with a different trend, due to the formation of alumina, confirmed by X-Ray Diffraction (XRD) measurements. Finally, the dependence of emissivity to temperature and oxide thickness emphasized in this paper constitutes a non-trivial mandatory input to increase the radiative heat transfer simulations codes accuracy.
\end{abstract}

\section{Introduction}

Among titanium alloys, Ti-6Al-4V alloy (also called TA6V) is one of the most widespread. Thanks to its low density (4.42 at $\left.20^{\circ} \mathrm{C}[1]\right)$, good corrosion resistance and excellent mechanical properties at elevated temperatures associated with a good formability, TA6V alloy is highly used in the aerospace industry [2]. Accordingly, it is used on helicopter blades [3], rotors [4] and turbojet manufacturing [5]. Numerous processes like forging [6], casting [7], hot [8] or superplastic forming [9] can be used to shape TA6V sheets. Moreover, this alloy is compatible with laser welding [10] although TA6V machining is widely acknowledged to be a difficult task [11]. TA6V alloy is usually shaped at high temperatures due to its high ductility. In order to obtain a high-quality part and to optimize forming processes, heat transfer computation is often used. The main reason for this interest is the impossibility to perform experimental exhaustive studies, due to the huge energy consumption of the process [12]. Moreover, the temperature of TA6V sheets must not overpass the socalled $\beta$-transus temperature (around $900{ }^{\circ} \mathrm{C}$ ) where a metallurgical

\footnotetext{
* Corresponding author.
}

phase transformation occurs and degrades permanently the mechanical properties of the final part. Accurate simulation is then a priority to ensure that the temperature of the TA6V sheet remains within an "acceptable" range. To do so, thermal boundary conditions and material properties should be known with a high precision. Emissivity is one of the required properties in hot forming processes because it governs radiation heat exchanges, especially when radiative alternatives processes are set up instead of conventional resistive ovens (see [13] for IR superplastic forming). The absorption and emission are then the core of the heat exchange. These optical properties are then required in order to assess the radiation heat transfer between surfaces [14]. Alternatively, spectral or integrated emissivity can also be needed for infrared temperature measurements (either with infrared cameras or pyrometers) operating within a specific spectral range. However, the measurement of emissivity remains a complex experimental task mainly because of the numerous influencing parameters: temperature, wavelength, surface roughness, oxidation and angle. As a consequence, emissivity can be described in several sub-categories: spectral/integrated/total emissivity when integrated over wavelength and directional/conical/ hemispherical emissivity when integrated over space, with the combination of each dependence [15]. Spectral directional emissivity 
is used for thermal measurements while total hemispherical emissivity is needed for heat transfer computation. This work focuses on one dynamic phenomena occurring during hot forming processes which has a great impact on emissivity value: namely oxidation. Indeed, the modification of the refractive index by a the generated oxide layer formed at the surface can multiply by 3 or 4 the initial emissivity of a metallic material [16]. Oxidation can also be responsible for interference phenomenon [17]. Therefore, performing coherent temperature measurements and accurate heat transfer computation inevitably require experimental evaluation of one of the given definition of emissivity.

TA6V alloy has a biphasic microstructure with 2 allotropic phases denoted respectively $\alpha$-phase and $\beta$-phase [18]. Oxide layer in TA6V is a complex combination of numerous chemical species [19] like $\mathrm{TiO}_{2}, \mathrm{Al}_{2} \mathrm{O}_{3}, \mathrm{TiVO}_{4}, \mathrm{VO}_{2}$ depending on thermal kinetics and temperature level... Nevertheless, in ranges comprised between 600 and $1000{ }^{\circ} \mathrm{C}$, this layer is mainly made up of rutile $\left(\mathrm{TiO}_{2}\right)$ and alumina $\left(\mathrm{Al}_{2} \mathrm{O}_{3}\right)[20,21]$. Alumina growth and proportion is directly linked with the rise of temperature and heating time [22]. At high temperatures and long oxidation times, TA6V oxide is a multi-layered structure formed by both rutile and alumina layers [20,23].

Spectral or total emissivity measurements under air atmosphere at high temperatures are scarce in the literature. Moreover, significant differences are seen on emissivity values depending on the source in literature which can be explained by differences between chemical composition, material surface roughness, experimental conditions... It is worth noting that significant differences are also seen for other properties like specific heat $[24,25]$ or thermal diffusivity [26].

González-Fernández et al. [27] investigated normal spectral emissivity under vacuum environment and for a thermal range between 273 and $877{ }^{\circ} \mathrm{C}$. Impact of material thermal history (temperature cyclings) on emissivity value was emphasized. Li et al. [28] investigated oxidation effect on directional spectral emissivity in Near InfraRed (NIR) range between 1.5 and $2.2 \mu \mathrm{m}$ and a thermal range between 550 and $700{ }^{\circ} \mathrm{C}$. A linear growth of emissivity versus heating time was shown at low temperatures $\left(\mathrm{T}<600{ }^{\circ} \mathrm{C}\right)$. Strong oscillations in emissivity versus heating time were shown for higher temperatures $\left(\mathrm{T}>650{ }^{\circ} \mathrm{C}\right.$ ). Those oscillations are explained by an interference effect within the oxide layer. Oscillations, especially visible in the first $20 \mathrm{~min}$, were also reported by Zhu [29] for a thermal range between 527 and $827^{\circ} \mathrm{C}$ and a wavelength of $1.5 \mu \mathrm{m}$. Transus $\beta$ effect on emissivity was also investigated by some works. Pagan [30] noted a significant drop of normal spectral emissivity at $960 \mathrm{~nm}$ beyond transus for a non-oxidized sample. However, several works [30-32] have shown that transus effect is reduced in the case of an oxidized sample. A significant drop of normal total emissivity at high temperature $\left(\mathrm{T}>1000{ }^{\circ} \mathrm{C}\right)$ is shown in Massuti-Ballester and Pagan [33] works. This fact was explained once again by transus effect. Barka [34] have shown the difficulty to have a good reproducibility on emissivity values at high temperatures due to oxide layer peeling. Even though those works are about the same material, emissivity values measured are quite different depending on the source (ranging from 0.5 to 0.71 in between the two aforementioned studies). This data dispersion is explained by different chemical compositions, roughness or heating method. The knowledge of the only dependence of emissivity to temperature seems insufficient especially under air atmosphere. Indeed, heating time has a strong effect on the oxide layer and considerably impacts the emissivity value. Associating emissivity to oxide layer which is a combination of both heating time and temperature effects seems a better solution to select an emissivity value.

The major contribution of this article is the use of an innovative characterization bench, based on a radiative image furnace, which reaches fast heating rates $\left(15^{\circ} \mathrm{C} / \mathrm{s}\right)$ and controlled thermal cycles up to $1200{ }^{\circ} \mathrm{C}$. On TA6V samples, oxide layers ranging from $250 \mathrm{~nm}$ to
Table 1

TA6V sample chemical composition.

\begin{tabular}{lllllllll}
\hline Element & $\mathrm{Al}$ & $\mathrm{V}$ & $\mathrm{C}$ & $\mathrm{Fe}$ & $\mathrm{O}$ & $\mathrm{N}$ & $\mathrm{Y}$ & $\mathrm{Ti}$ \\
\hline Part (\%) & 6.47 & 3.94 & 0.015 & 0.18 & 0.16 & 0.001 & $<0.001$ & Balance \\
\hline
\end{tabular}

$120 \mu \mathrm{m}$ are obtained in relation with temperature and oxidation time. The final calculation of integrated emissivity helps to understand the link between oxide layer thickness and radiative heat exchange in hot metal forming properties.

In the first part of this paper, experimental set-up which consists of a specific device developed in previous works $[35,36]$ is presented. The second part details the oxidation kinetics of the selected TA6V sample. Directional spectral emissivity and directional integrated emissivity are then measured in the third part, for several temperature levels and oxidation times. Finally, emissivity values are summarized and their dependence to oxide layer thickness are investigated.

\section{Experimental set-up}

\subsection{Sample characteristics}

Samples used in this study are disk-shaped with a diameter of $10 \mathrm{~mm}$ and a thickness of $1.5 \mathrm{~mm}$. Samples were cut by waterjet from a rolled TA6V sheet. The chemical composition of the specimens is presented in Table 1.

Surface roughness measurements were performed with a Altimet/STIL ${ }^{\circledR}$ confocal microscope (Altisurf A520) and are presented in Table 2. The value of Sa and $\mathrm{Sq}$ are presented along with the classical roughness $\mathrm{Ra}$ and $\mathrm{Rq}$ since they provide valuable information on the surface flatness (absent from the Ra and Rq calculations). The equipment accuracy is inferior to $1 \%$.

\subsection{Emissivity measurement method and device}

The device used in this paper (Fig. 1) was detailed in a previous paper [35]. It consists of an elliptical furnace with an IR lamp located on the first focal point while the sample is put on the second focal point. This particularity allows interesting thermal performances with temperatures superior to $1000{ }^{\circ} \mathrm{C}$ on the sample and a heating rate around $15{ }^{\circ} \mathrm{C} / \mathrm{s}$. Moreover, this set-up allows versatility on both heating rate and atmospheric conditions. Measurements are based on direct method for both spectral directional and integrated directional emissivity and a thermal range of $600-1000{ }^{\circ} \mathrm{C}$. As a reminder, direct method [37] is a comparison method that enable the assessment of the emissivity by measuring both sample and blackbody emission at the same temperature and then applying the definition of emissivity [14].

NIR measurements in $\mathrm{BI}=[1.3-2.5] \mu \mathrm{m}$ are performed through a NEOSPECTRA ${ }^{\circledast}$ IRTF spectrometer equipped with an optical fiber. The area seen by the optical fiber aperture put at $2.5 \mathrm{~mm}$ higher than the sample is a $6 \mathrm{~mm}$ diameter circle. In the case of Middle InfraRed $(\mathrm{MIR})(\mathrm{BII}=[2.5-5] \mu \mathrm{m}$ and BIII= [7.5-13] $\mu \mathrm{m})$ measurements, IR cameras (resp. FLIR ${ }^{\circledast}$ SC7000 and FLIR ${ }^{\circledR}$ SC325) equipped with interference filters are used. Focal lengths of the lenses used are resp. $50 \mathrm{~mm}$ and $30 \mathrm{~mm}$, Regions Of Interest (ROIs) are chosen to fit with

Table 2

Waviness and roughness values.

\begin{tabular}{lllll}
\hline \multicolumn{2}{l}{ Waviness and roughness } & & \multicolumn{2}{l}{ Roughness } \\
\cline { 1 - 2 } \cline { 5 - 5 } Sa $(\mu \mathrm{m})$ & Sq $(\mu \mathrm{m})$ & & $\begin{array}{l}\text { Ra }(\mu \mathrm{m}) \\
\text { filter } 0.8 \mathrm{~mm}\end{array}$ & $\mathrm{Rq}(\mu \mathrm{m})$ filter $0.8 \mathrm{~mm}$ \\
\hline 0.485 & 0.641 & 0.5422 & 0.6922 \\
\hline
\end{tabular}




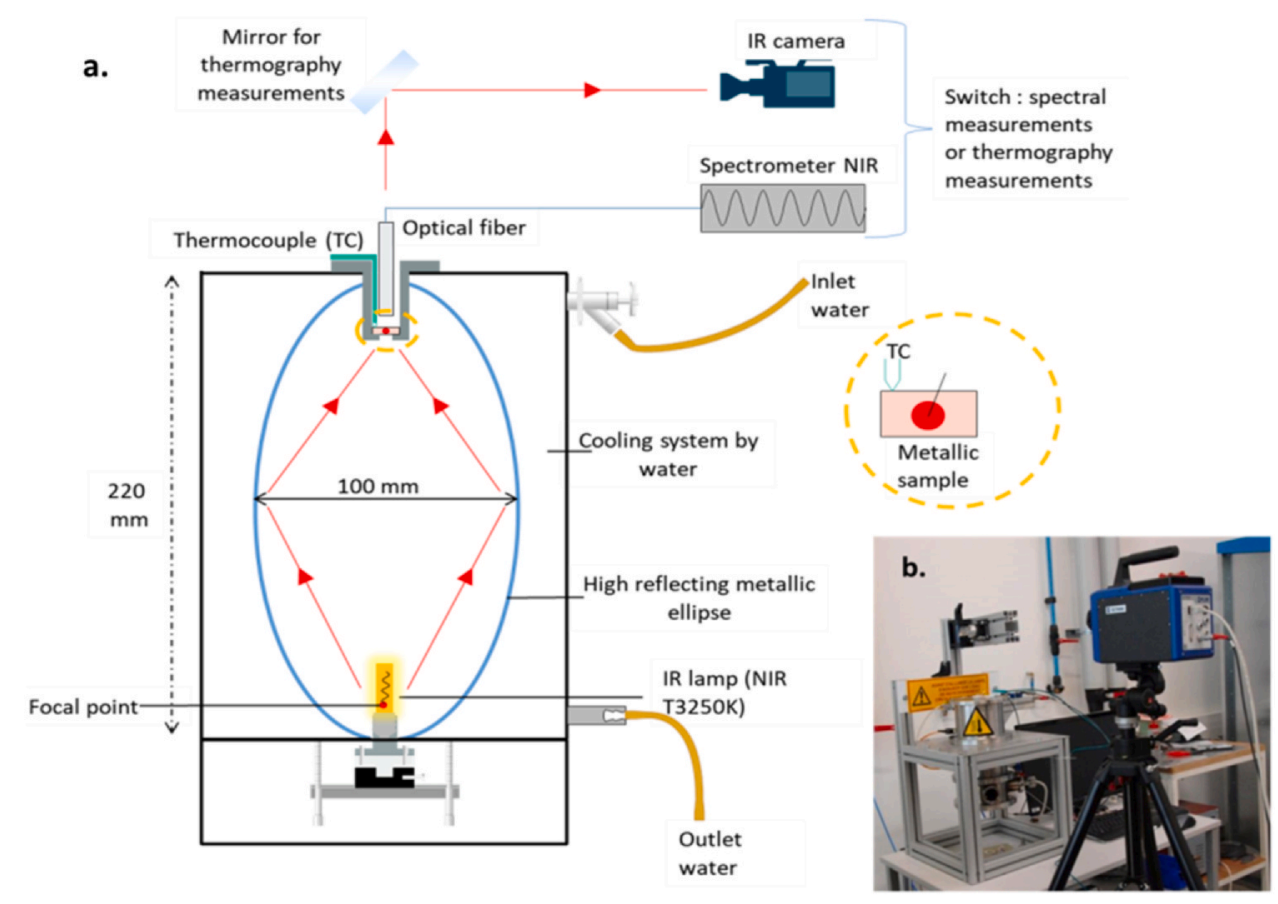

Fig. 1. Experimental set-up; a. cross section view; b. Photograph.

Table 3

Sensors characteristics.

\begin{tabular}{lllll}
\hline Range & NIR BI & MIR BII & & MIR BIII \\
Device & Spectrometer & IR Camera & & IR Camera \\
Wavelength $(\mu \mathrm{m})$ & {$[1.3 ; 2.5]$} & $3.027 \quad 4$ & 5.071 & 10 \\
\hline
\end{tabular}

BI surface detection (6 mm diameter circle - around 50 pixels). Sensors characteristics are detailed in Table 3.

The first step for integrated emissivity computation is the concatenation and interpolation of each spectral band. Directional spectral emissivity $\left(\varepsilon_{\lambda}^{\vec{r}}(T)\right)$ is first calculated for each band through the ratio of emitted signals measured in the sample and the blackbody at the same temperature. Note that an important void exists between MIR BII and MIR BIII (almost $5 \mu \mathrm{m}$ ), as seen in Fig. 2. However, this spectral band is not contributing much on the emission spectrum in the thermal range of this study. Firstly, at $1000^{\circ} \mathrm{C}$, the maximum emission wavelength is located at $2.26 \mu \mathrm{m}$ and at $3.32 \mu \mathrm{m}$ for $600{ }^{\circ} \mathrm{C}$. Secondly, the emissivity for metals is always spectrally decreasing, emphasizing once more the contribution of short wavelengths. Finally, the presence of a strong absorption band

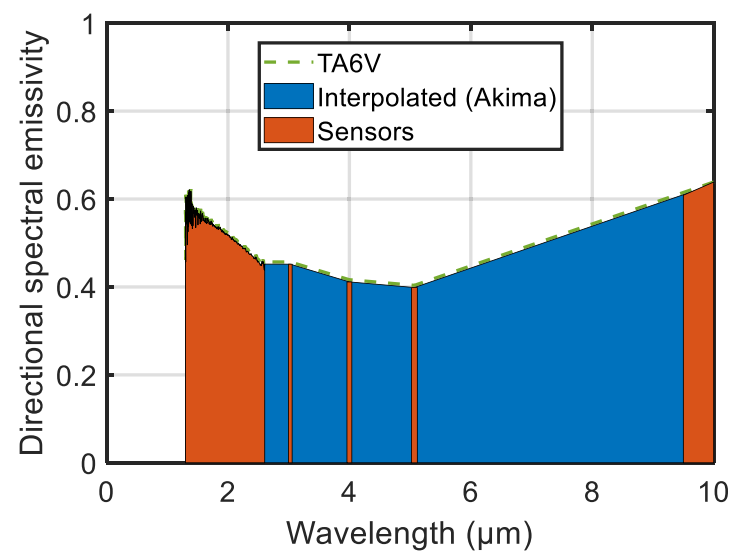

Fig. 2. TA6V directional spectral emissivity at $900{ }^{\circ} \mathrm{C}$. of water $(5-8 \mu \mathrm{m})$ in air makes the radiative measurement difficult in this spectral domain. High experimental errors are then expected.

An interpolation approach is then selected, using the Akima spline interpolant [38], showing lesser interpolation errors in comparison to linear or classical spline was chosen [36]. The calculation is then performed following next equation:

$\varepsilon^{\vec{r}}(T)=\frac{\int_{\lambda_{1}}^{\lambda_{2}} \varepsilon_{\lambda}^{\vec{r}}(T)^{*} L^{0}(\lambda, T)^{*} d \lambda}{\int_{\lambda_{1}}^{\lambda_{2}} L^{0}(\lambda, T)^{*} d \lambda}$

With $\varepsilon^{\vec{r}}(T)$ the directional integrated emissivity, $\varepsilon_{\lambda}^{\vec{r}}(T)$ the directional spectral emissivity, $\lambda$ the wavelength in $\mu \mathrm{m}, T$ the temperature measurement, $L^{0}(\lambda, T)$ the spectral intensity emitted by the blackbody.

One of the drawbacks of the geometrical configuration imposed by the use of an image furnace and a ceramic sample holder is the presence of spurious signals. Indeed, the sample holder is also heated on its lower part and induces parasite radiation emitted either directly to the detectors, or reflected by the sample. The bias introduced by such unintended radiation implies to set up a correction method to retrieve coherent values [37]. Spurious signals were determined for NIR measurements by using a reference material (namely polished platinum). Polished platinum was chosen in view of its constant spectral emissivity versus the temperature [39,40]. In the MIR range, the use of IR cameras allows the insertion of a pipe to obstruct spurious signals [35]. The complete method allowing spurious signals removal in emissivity calculation is detailed in $[35,36]$.

\subsection{Experimental procedures}

The temperature range was chosen to overlap several hot forming applications like forging, hot stamping, SPF forming... Heating time of one hour was chosen which allows applying those measurements for rapid processes like forging or slower processes like IR SPF forming. However, some works in literature $[28,29]$ have shown that TA6V emissivity between 600 and $827^{\circ} \mathrm{C}$ grows steadily until $200 \mathrm{~min}$ of heating but much slowly beyond. Therefore, a whole 
Table 4

Experimental conditions for emissivity measurements.

\begin{tabular}{lllllll}
\hline $\mathrm{T}\left({ }^{\circ} \mathrm{C}\right)$ & 600 & 700 & 800 & 900 & 1000 & 1000 \\
\hline Cycle time $(\mathrm{min})$ & 60 & & & & & 300 \\
Time interval $\Delta \mathrm{t}(\mathrm{min})$ & 6 & & & & & 30 \\
Atmosphere & Air & & & & & \\
\hline
\end{tabular}

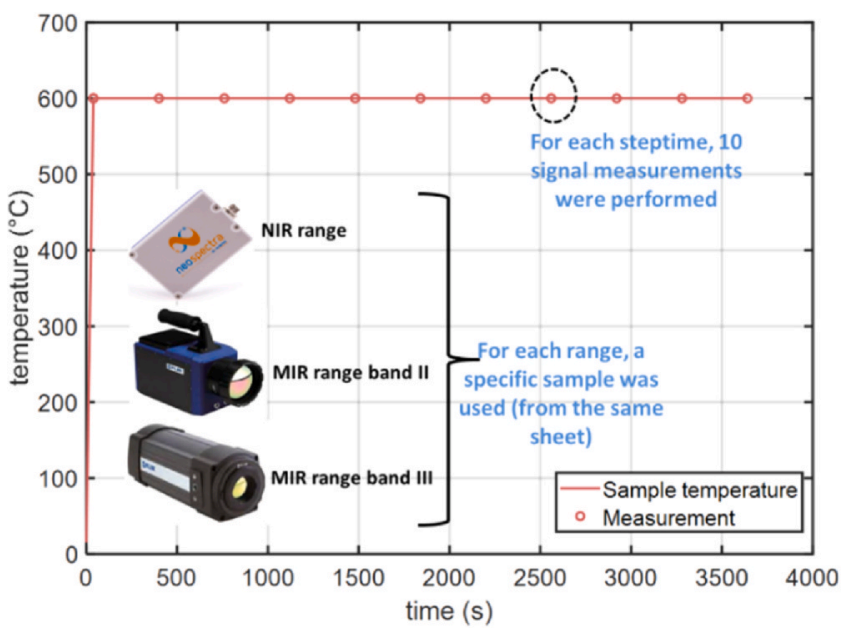

Fig. 3. Experimental procedure for emissivity measurement at $600{ }^{\circ} \mathrm{C}$.

heating time of five hours at $1000^{\circ} \mathrm{C}$ was added in order to highlight its effect on emissivity value.

All the samples used in this study are cut from the same sheet. For each temperature and time increment, 10 signal measurements were performed. The choice of sensors (Table 4) does not allow simultaneous measurements within the three spectral bands defined in Table 3. Given the measurement device configuration, signals emitted by the sample were measured separately for each sensor at a given temperature. Therefore, a new sample was used for each range. Blackbody signals used for emissivity calculation were measured for each sensor through a blackbody LAND ${ }^{\circledR}$ R1500T with an emissivity of 0.99 . The experimental procedure is summarized in Fig. 3.

\section{Oxidation of TA6V alloy}

This section investigates the oxidation kinetics of TA6V in order to anticipate the emissivity variations encountered in the final section. Thanks to mass gain and oxide layer thicknesses measurements, an oxidation law is parametrized and enables the computation of oxide thickness for every time and temperature. Moreover, XRD characterization is performed on post mortem samples to state about the chemical structure of the top surface.

\subsection{Samples appearance after heating}

In order to emphasize the strong variation of the oxide layer thickness with temperature, post mortem samples surface photographs (Fig. 4) were taken.

As shown in Fig. 4, the surface appearance changes significantly following the temperature and/or the heating time. The oxide layer at $600{ }^{\circ} \mathrm{C}$ is iridescent, suggesting that visible wavelengths interfere in the oxide layer, and the different colors reveal a thickness gradient on the surface. The oxide seems thicker on the right hand side of the sample which corresponds to the localization of the heating beam (slightly shifted to the right part of the sample). Note that the color is governed by constructive interferences, which appear when the
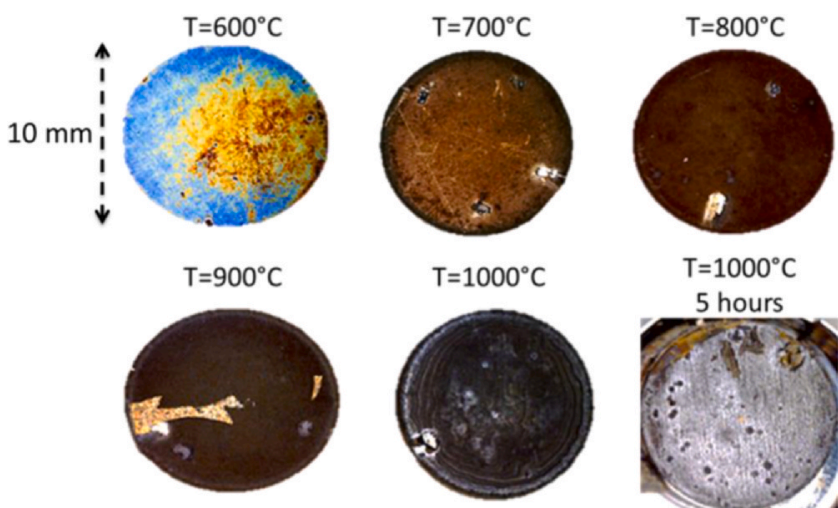

5 hours

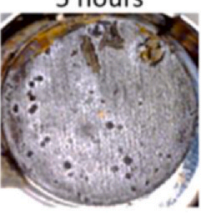

Fig. 4. TA6V samples (10 mm diameter) after heating.

thickness is equal to half wavelength multiplied by a positive integer:

$n^{*} e=k \frac{\lambda}{2}$ with $\mathrm{k}=1,2, \ldots, \mathrm{N}$

If limiting the $\mathrm{k}$ factor to 2 , one can infer that the oxide layer thickness is here in the same order of magnitude than the visible wavelength, i.e. $<800 \mathrm{~nm}$. The other condition of interference appearance is that the oxide layer must be semitransparent, which is the case for both $\mathrm{Al}_{2} \mathrm{O}_{3}$ and $\mathrm{TiO}_{2}$.

At 700 and $800^{\circ} \mathrm{C}$, the surface color is being homogeneously brown and becomes darker as the temperature increases. Surface color at $900{ }^{\circ} \mathrm{C}$ is also brown, a part of the oxide layer has peeled off and the sublayer can then be seen below. The aspect at $1000^{\circ} \mathrm{C}, 1 \mathrm{~h}$ is different and tends to a dark grey, but after $5 \mathrm{~h}$ of oxidation, color changes to a light gray, with an oxide layer that can be easily removed. The change from brown to dark and light grey supposes that the oxidation chemical structure might have changed.

To sum up, the visible features of the oxide layer greatly vary with both temperature and heating time. Accordingly, it is reasonable to assume that the sample surface optical behavior and induced emissivity may vary alike in other wave ranges. Hence, linking emissivity to oxidation kinetics through layer thickness and constitution rather than time and temperature might prove more interesting.

\subsection{Background on kinetic oxidation laws}

The aim of this oxidation study is to evaluate an oxide thickness for each temperature and time. The fundamental law linking oxide thickness with heating time is given by the so-called parabolic law, often encountered to describe TA6V oxidation [41]:

$\left(\frac{\Delta m}{A}\right)^{2}=k_{p}(T)^{*} t$

With $k_{p}$ the parabolic rate constant in $\mathrm{kg}^{2} \mathrm{~m}^{-4} \mathrm{~s}^{-1} ; \Delta m$ the mass gain in $\mathrm{kg} ; A$ the area in $\mathrm{m} 2 ; t$ the oxidation time in $\mathrm{s}$. Note that this law fits correctly the oxide layer growth of a single oxide, but is limited for complex oxidation kinetics as multiple oxide layers growth with possible oxygen diffusion mitigation.

The computation of the oxide thickness is possible if: 1) $k_{p}$ is known for each temperature; 2) The mass density of the oxide is known (in order to convert mass gain to oxide thickness). Those parameters are deduced from post mortem $(t=1 \mathrm{~h})$ measurements of: 1) mass gain by precision balance; 2) Scanning Electron Microscopy (SEM) cross section observations to measure oxide thickness. Density is then inferred by dividing the mass gain with the volume occupied by the oxide layer. To do so, a hypothesis of uniform oxide thickness has been adopted (commonly used in 
oxidation kinetics studies), coupled with a second hypothesis stating that the entire mass gain is comprised in the oxide thickness (no volume mass gain). This latter hypothesis supposes that the weight gain due to phenomena like oxygen dissolution in the TA6V substrate ( $\alpha$-case formation) is negligible compared to oxide layer formation. Finally, using the Arrhenius law and performing a linear regression on the logarithm of the parabolic rate, it is possible to identify the parabolic rate constant at $0 \mathrm{~K} k_{p 0}$ and the activation energy $E$.

$k_{p}=k_{p 0} \exp \left(\frac{-E}{R T}\right)$

With $k_{p 0}$ the parabolic rate constant limit at $0 \mathrm{~K}$ in $\mathrm{kg}^{2} \cdot \mathrm{m}^{-4} \cdot \mathrm{s}^{-1} ; E$ the activation energy in $\mathrm{J} \cdot \mathrm{mol}^{-1} ; R$ the gas constant $=8.314 \mathrm{~J} \cdot \mathrm{mol}^{-1}$. $\mathrm{K}^{-1} ; T$ the temperature in $\mathrm{K}$.

The identification of the oxidation law $\left(E\right.$, and $k_{p}$ ) enables the computation of the instantaneous oxide layer thickness for each heating time and temperature.

\subsection{Instantaneous oxide layer thickness results}

TA6V samples were weighted before and after heating with a SARTORIUS $^{\circledR}$ micro weighting balance (model MC5) with a maximum deviation of $10 \mu \mathrm{g}$. Mass gain deduced for each temperature after one hour heating are presented in Fig. 5. Mass gain is found to increase exponentially with temperature, which is in accordance with the Arrhenius law [42]. The comparison with values from Dong [23] shows a similar trend for the mass gain versus temperature. The gap between those curves can be explained by a different heating method (air muffle furnace in Dong's work) and differences in chemical compositions.

In the same way, oxide thickness after heating is measured on a cross section cut with a FEI NOVANANOSEM scanning electron microscope. The observation is realized using a secondary electron detector, with an acceleration voltage of $15 \mathrm{kV}$. With this configuration and at $\mathrm{x} 500$ magnification, the resolution of the device is estimated at $2 \mathrm{~nm}$ maximum. Measured thicknesses after one hour of heating are presented in Fig. 6b. Oxide thickness and mass gain curves follow a similar trend with regard to temperature. A sharp rise is shown for temperatures higher than $800^{\circ} \mathrm{C}$.

Oxide thickness and mass gain values after heating are presented in Table 5.

Oxide thickness and mass gain show a high dependency to heating time. Indeed, the oxide thickness value at $1000^{\circ} \mathrm{C}, 5 \mathrm{~h}$ is 2.4 higher than the one found for $1 \mathrm{~h}$. The value at $600^{\circ} \mathrm{C}$ is consistent with the appearance of visible interference noticed on optical microscopy photographs (Fig. 4), with a thickness of $780 \mathrm{~nm}$,

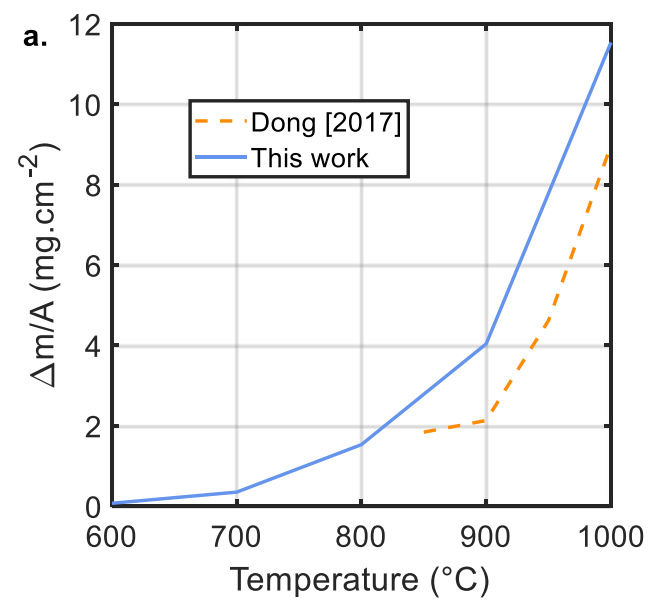

Fig. 5. Mass gain versus temperature after one hour of heating. corresponding to a deep red color. Knowing the thickness and the mass gain, it is possible to determine the parabolic rate constant $k p$ for each temperature.

$k_{p}$ constants calculated from Eq. (2) are presented in Table 6.

The two $k_{p}$ values obtained for the conditions $\left(1000^{\circ} \mathrm{C}, 1 \mathrm{~h}\right)$ and $\left(1000^{\circ} \mathrm{C}, 5 \mathrm{~h}\right)$ are different, contrary to what Arrhenius law suggests (see Eq. 3). This drift can be explained by the modification of the oxidation kinetics for long times, which moves away from a parabolic rate to a linear trend, as noticed in [43]. $E$ and $k p_{0}$ parameters can be identified by rewriting Arrhenius law (Eq. (2)) in a logarithmic form, and performing a linear regression of $\log \left(k_{p}\right)$ versus 1 / $T$. The value of the coefficient of correlation is equal to 0.998 , testifying of the physical consistency of the measurement. The values of the coefficients are displayed in Arrhenius law:

$k_{p}=9.62^{*} 10^{4 *} \exp \left(\frac{-232792}{R^{*} T}\right)$

This activation energy is consistent with values determined by Guleryuz et al. [44] (between 191 and $276 \mathrm{~kJ} \mathrm{~mol}^{-1}$ ) in their works on TA6V oxidation and those determined by Dong [23] (between 199 and $281 \mathrm{~kJ} \mathrm{~mol}^{-1}$ ). The resulting deviations can be explained by slightly different thermal cycles (environmental conditions) and/or initial TA6V composition.

The re-arrangement of Eq. (2) with the introduction of density enables the computation of oxide thickness, for each time and temperature:

$e \quad(t, T)=\frac{\sqrt{k_{p}{ }^{*} t}}{\rho^{*}(T)}$

Where $\rho^{*}$ is the apparent density of oxide layer calculated from the measurement of both mass gain and oxide thickness after heating. Note that this density is apparent because porosities and multiple layers are not considered, as the main objective is to predict oxidation kinetics and oxide thickness. In no way these results are to be compared with dense oxide properties. This parameter may differ from real density because of the approximation of a unique homogeneous oxidation layer, whereas TA6V tends to form stack-up structures composed of $\mathrm{TiO}_{2}, \mathrm{TiVO}_{4}$ and $\mathrm{Al}_{2} \mathrm{O}_{3}$. Thicknesses calculated from this law (Eq. (6)) are displayed for each temperature, for each measurement time, in Fig. 7.

The influence of the heating time on oxide thickness increases as temperature rises, but not in a monotonous manner. Indeed, it increases more between 800 and $900{ }^{\circ} \mathrm{C}$ than between 900 and $1000^{\circ} \mathrm{C}$. This phenomenon can be linked with an oxide layer thick enough to mitigate oxygen diffusion toward the substrate, which slows down the oxidation phenomena. Also, the alignment of curves for $1000^{\circ} \mathrm{C}, 1 \mathrm{~h}$ and $1000^{\circ} \mathrm{C}, 5 \mathrm{~h}$ is remarkable and proves the accuracy of the thermal cycles involved and the repeatability of the conditions between two tests on two different samples.

To summarize, a wide range of oxide layer from $250 \mathrm{~nm}$ to $120 \mu \mathrm{m}$ can be investigated and analyzed in parallel with emissivity values. Note that the temperatures 700 and $800{ }^{\circ} \mathrm{C}$ look favorable to interference formation in our spectral bands (referring to Eq. (1)), accordingly precautions must be taken in the analysis at such temperatures. In conclusion, the oxide thickness is determined for each temperature and time step and will be linked with corresponding emissivities in part 4.

\subsection{XRD measurements}

To figure out which chemical oxide is present at the top surface of the sample, an XRD analysis is performed at grazing angle to reduce substrate influence of the diffractogram. The equipment under use is a Philips X'PERT diffractometer. Fig. 8 presents XRD patterns of oxidized samples after heating. 

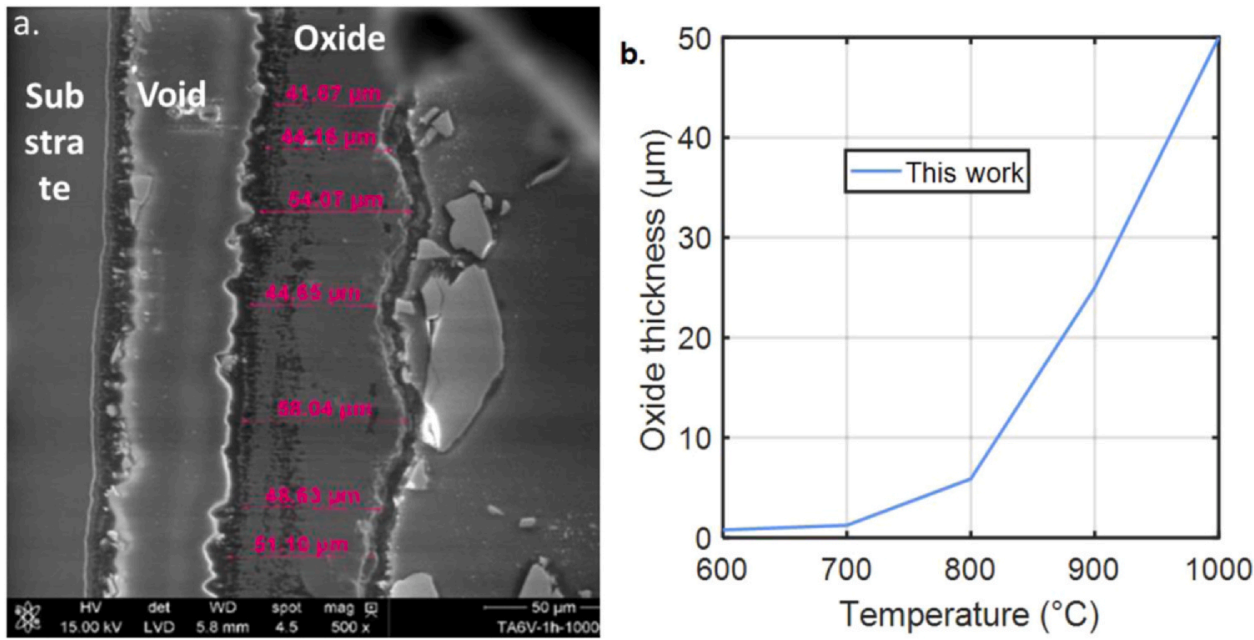

Fig. 6. a. SEM photography of oxide layer measurement for $\mathrm{T}=1000^{\circ} \mathrm{C}, \mathrm{t}=1 \mathrm{~h}$; b. Oxide thickness versus temperature after one hour of heating.

Table 5

Mass gain and oxide thickness values after heating.

\begin{tabular}{lclllll}
\hline $\mathrm{T}\left({ }^{\circ} \mathrm{C}\right)$ & 600 & 700 & 800 & 900 & 1000 & 1000 \\
\hline $\mathrm{t}(\mathrm{min})$ & 60 & & & & & 300 \\
Mass gain $(\mathrm{mg})$ & 0.114 & 0.550 & 2.405 & 6.341 & 18.112 & 48.553 \\
Oxide thickness $(\mu \mathrm{m})$ & 0.78 & 1.24 & 5.88 & 25 & 50 & 120 \\
\hline
\end{tabular}

The presence of $\mathrm{TiO}_{2}$, alumina and $\mathrm{TiVO}_{4}$ oxide is observed, which is in accordance with several published works $[19,21,22]$. $\mathrm{TiVO}_{4}$ peaks were not displayed for a better reading as $\mathrm{TiO}_{2}$ and $\mathrm{TiVO}_{4}$ peaks are merged due to an identical stoichiometry. Rutile presence is noted for all heating temperatures. A sharp increase of peak intensities is observed as the temperature rises. Alumina presence is noted starting from $900{ }^{\circ} \mathrm{C}$. Peak intensities increase with temperature in the same way than $\mathrm{TiO}_{2}$. Moreover, heating time also causes a rise of peak intensities as seen for measurements done at $1000^{\circ} \mathrm{C}-5 \mathrm{~h}$. These observations are consistent with literature given that alumina presence and proportion is strongly impacted by heating time and temperature. Indeed, the presence of alumina in the oxide layer below $900{ }^{\circ} \mathrm{C}$ would require significant heating time (higher than those chosen in the present paper). To sum up: below $900{ }^{\circ} \mathrm{C}$, the oxide layer is mainly composed of rutile $\mathrm{TiO}_{2}$, whereas above this temperature, alumina $\mathrm{Al}_{2} \mathrm{O}_{3}$ gets more are more significant at the top surface.

\section{Emissivity measurements}

\subsection{Spectral emissivity measurements}

\subsubsection{Emissivity measurements for a heating time of one hour}

Directional spectral emissivities measured following the method detailed in part 2.3, and the one measured after the heat treatment, at room temperature, with a Fourier Transform InfraRed (FTIR) spectrometer Bruker Vertex 70, are displayed in Fig. 9.

Emissivity value increases as the temperature rises. At $600{ }^{\circ} \mathrm{C}$, the spectrum displays a monotonous spectral decrease, typical of metallic materials, inferring that the oxide layer is optically negligible. However, at $10 \mu \mathrm{m}$, a slight increase of spectral emissivity suggests

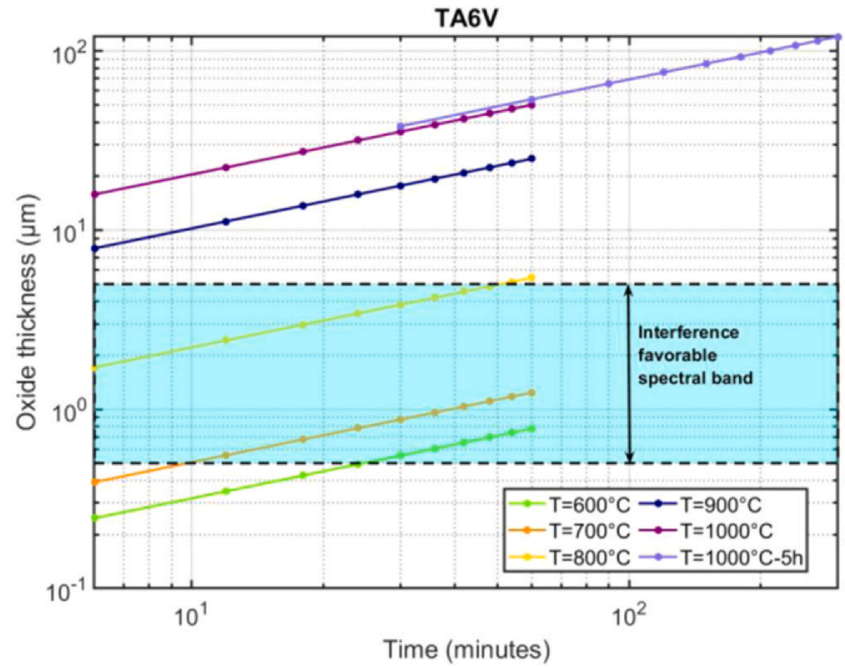

Fig. 7. Oxide thickness versus heating time and temperature.

that a thin oxide layer is present, as this wavelength is known as a high-absorption band for Rutile [45]. After one hour at $600{ }^{\circ} \mathrm{C}$, the emissivity is globally increased by $60 \%$, which again is the signature of the Rutile layer. The a posteriori measured emissivity is higher and this difference can be explained by the poor Signal to Noise Ratio (SNR) at this temperature and/or by the effect of temperature on emissivity for little oxidized metals.

The 700 and $800{ }^{\circ} \mathrm{C}$ spectra show very different behavior, due to the interferences formation inside the oxide layer, according to Fig. 5. This is particularly visible at $3 \mu \mathrm{m}$, where emissivity seems to reach a local maximum. The value at $10 \mu \mathrm{m}$ also increases as the oxide layer increases. The difference with the FTIR spectrum is still important, but is not surprising due to the interference favorable spectral domain. However, for the final time at $800^{\circ} \mathrm{C}$, which corresponds to the end of interferences with an oxide layer thickness around $6 \mu \mathrm{m}$, it is noticeable that the two spectra get closer. This phenomena also occurs for the higher temperatures.

Table 6

Parabolic rate constants calculated for TA6V alloy.

\begin{tabular}{|c|c|c|c|c|c|c|}
\hline$T\left({ }^{\circ} \mathrm{C}\right)$ & 600 & 700 & 800 & 900 & 1000 & 1000 \\
\hline$t(\mathrm{~h})$ & 1 & 1 & 1 & 1 & 1 & 5 \\
\hline$k_{p}\left(\mathrm{~kg}^{2} \cdot \mathrm{m}^{-4} \cdot \mathrm{s}^{-1}\right)$ & $5.85 * 10^{-10}$ & $1.36 * 10^{-8}$ & $2.61 * 10^{-7}$ & $1.81 * 10^{-6}$ & $1.48 * 10^{-5}$ & $2.12 * 10^{-5}$ \\
\hline
\end{tabular}




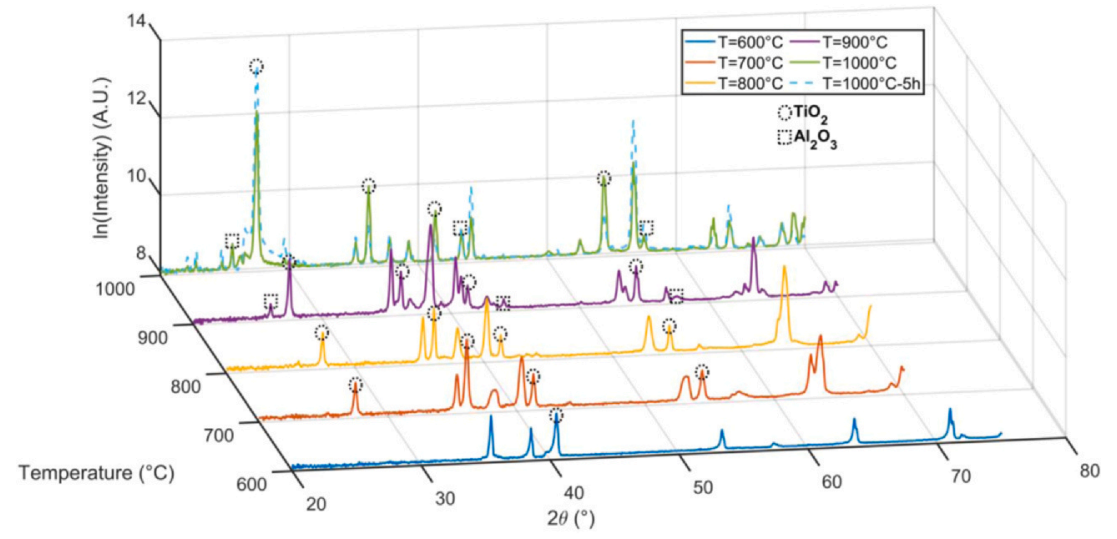

Fig. 8. XRD patterns of samples oxidized after heating.

The spectra at 900 and $1000{ }^{\circ} \mathrm{C}$ are also different and correspond to Alumina formation, with a value at $10 \mu \mathrm{m}$ tending towards 1 , which suggests the Christiansen point of Alumina [46]. Heating time effect on emissivity is less significant at high temperatures which can be explained by a much faster development of the oxide layer. This phenomena also informs that the thickness of the oxide layer (between 20 and $50 \mu \mathrm{m}$ ) is superior to the average free path of photons in the oxide layer, and that the radiation only comes from the top surface (i.e. the metallic substrate has no influence anymore). Room temperature FTIR spectrum, for those temperatures, is very close to the one measured by the method developed in this article.

Ten signal measurements were done at each temperature and heating time. Relative uncertainty on emissivity measurements are calculated considering the noise of spectrum measurements for both sample and blackbody. Impact of spurious signals caused by the environment contribution on emissivity measurement was also taken into account. Environment contribution is mainly caused by signals emitted or reflected by the sample holder. A method to evaluate those spurious signals is detailed in a previous paper [35]. Relative uncertainties calculated by taking those parameters into account are presented for each temperature and heating time in Fig. 10.
Uncertainty is maximal at $600{ }^{\circ} \mathrm{C}$ and low wavelengths because of a poor signal-to-noise ratio. Indeed, sample emission for a blackbody is contained between [1.66-16.6] $\mathrm{m}$ at $600{ }^{\circ} \mathrm{C}$ and [1.13-11.3] $\mu \mathrm{m}$ at $1000{ }^{\circ} \mathrm{C}$ according to Wien's law. Moreover, at $600{ }^{\circ} \mathrm{C}$, oxidation is weak and the emissivity of TA6V is low. For the other heating times and temperatures, uncertainties remain globally low, because of the rise of the signal value thanks to temperature and emissivity value enhanced by oxidation. Except for the conditions where the signal to noise ratio is poor, the relative uncertainty on emissivity is low and reinforces the physical consistency of the emissivity spectra measurement.

\subsubsection{Emissivity measurements for a heating time of $5 \mathrm{~h}$}

Directional spectral emissivity measured at $1000{ }^{\circ} \mathrm{C}$ for a heating of $5 \mathrm{~h}$ is displayed in Fig. 11.

Relative uncertainty is low with a maximum of $3.5 \%$ at low wavelengths. Once again, emissivity tends towards 1 at $10 \mu \mathrm{m}$ which is an indication of a Christiansen point of alumina. Indeed, Rozenbaum et al. [47] have identified this wavelength near $9.7 \mu \mathrm{m}$. This statement can be confirmed by an emissivity measurement done (Fig. 12) through a spectrometer Bruker Vertex 70 for the samples used in Fig. 11 after heating. An integrating sphere equipped with InGaAs
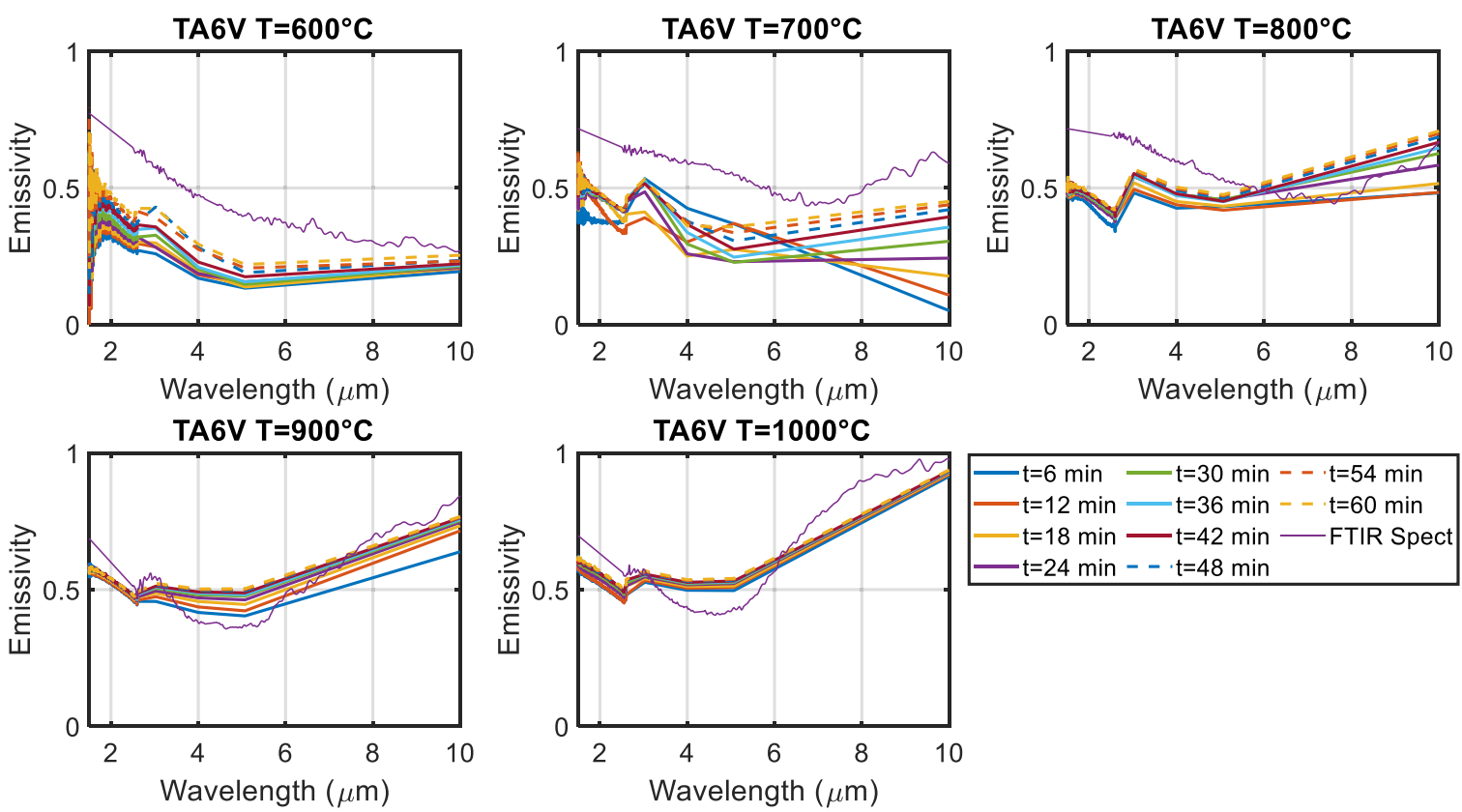

Fig. 9. Spectral emissivity for a heating time of one hour. 

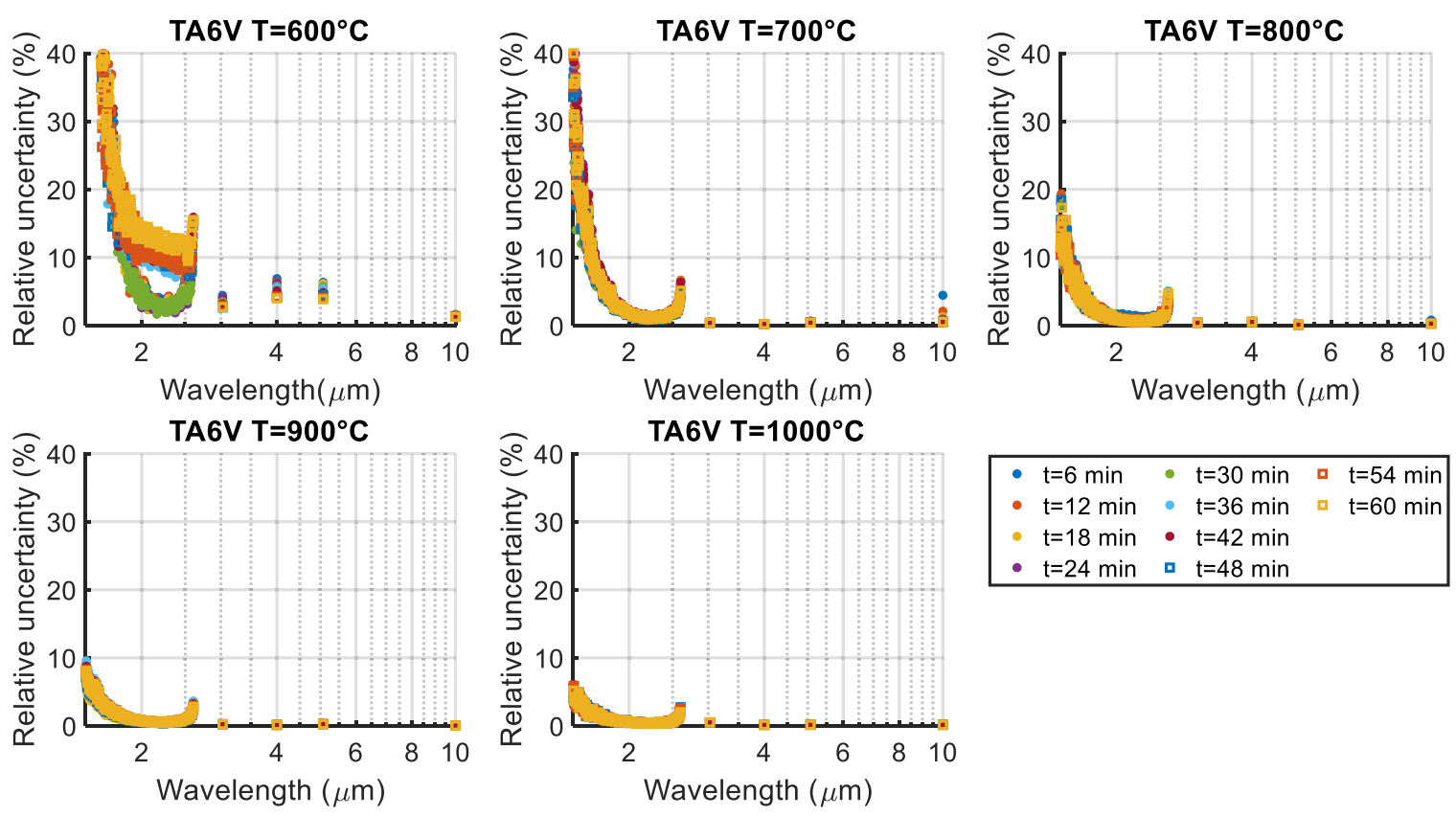

Fig. 10. Relative uncertainty versus temperature for a heating time of one hour.

detector for NIR range and DLaTGS detector for MIR range was used to perform those measurements.

The reflectance tends toward 0 around $10 \mu \mathrm{m}$ which confirms the presence of alumina's Christiansen point. This appearance of alumina's Christiansen point at high temperature is consistent with several works about TA6V oxidation demonstrating that alumina proportion is directly linked with the temperature and heating time increase [21,22].

\subsection{Integrated directional emissivity measurements}

Integrated directional emissivities are calculated from spectral emissivity measurements done in part 4 and by using Eq. (1). They are displayed in Fig. 13.

Oscillations are noticed at 600 and $700{ }^{\circ} \mathrm{C}$ which is once again a signature of the semi-transparency of the thin oxide layer. These oscillations disappear after $20 \mathrm{~min}$ in the same order of magnitude than Li [28] and Zhu [29] works. Temperature has a strong influence under $800^{\circ} \mathrm{C}$ but is less significant beyond, where the oxide layer thickness is superior to the photon average free path. Heating time is highly significant for the first $20 / 30 \mathrm{~min}$. Furthermore, its influence decreases with temperature which is also linked to the oxide thickness. Note that this kind of interpolated data can constitute a very precious input for simulation studies, where both time-dependent and thermal-dependent properties are often required.

Finally, these measurements have to be compared to emissivity values extracted from the literature and also measured under air atmosphere (Fig. 14).

The values measured in this paper are consistent with the literature data for temperatures higher than $700{ }^{\circ} \mathrm{C}$. Once again, discrepancy on emissivity values regarding the source is noticed. For instance, in Milosevic work, integrated emissivity is equal to 0.7 with a thermal constancy. On the contrary, in this work, it goes from 0.3 at $600{ }^{\circ} \mathrm{C}$ to 0.55 at $1000{ }^{\circ} \mathrm{C}$. These differences can be explained by different heating techniques, samples (pre-oxidized...), chemical compositions, and surface preparation....

Then, it seems relevant to link emissivity with oxide thickness rather than temperature or heating time. In order to do this, oxide thicknesses calculated and displayed in Fig. 7 are used to draw an emissivity vs. oxide thickness diagram (Fig. 15).

This graph can be segmented in two domains. The first one is the interference one, for temperatures of 700 and $800{ }^{\circ} \mathrm{C}$, and where layer thickness creates interferences in our spectral detection band. The other domain, located at each part of the interference domain,
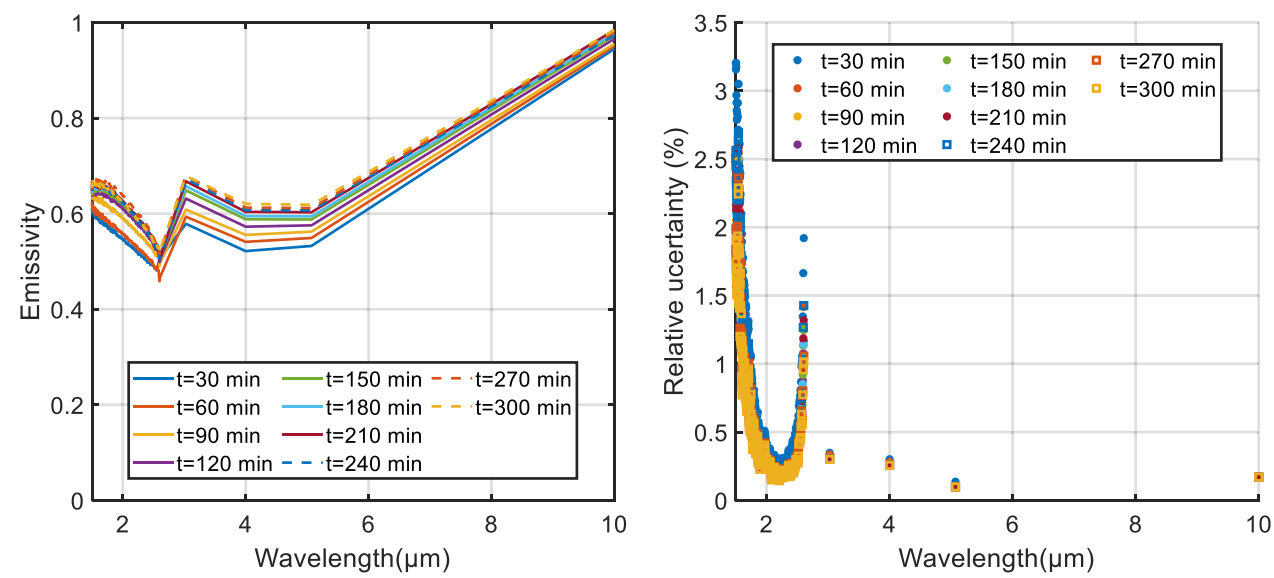

Fig. 11. Emissivity versus temperature for a heating time of $5 \mathrm{~h}$ (left side); relative uncertainty (right side). 


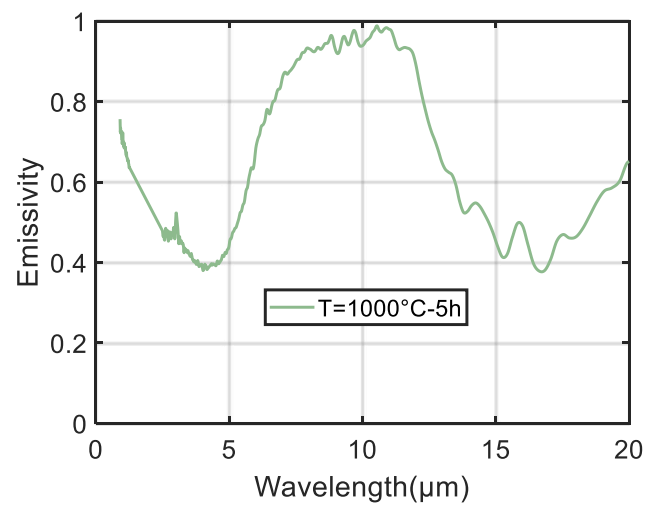

Fig. 12. Emissivity measured through a spectrometer Bruker Vertex 70 after a heating time of $5 \mathrm{~h}$ at $1000^{\circ} \mathrm{C}$.

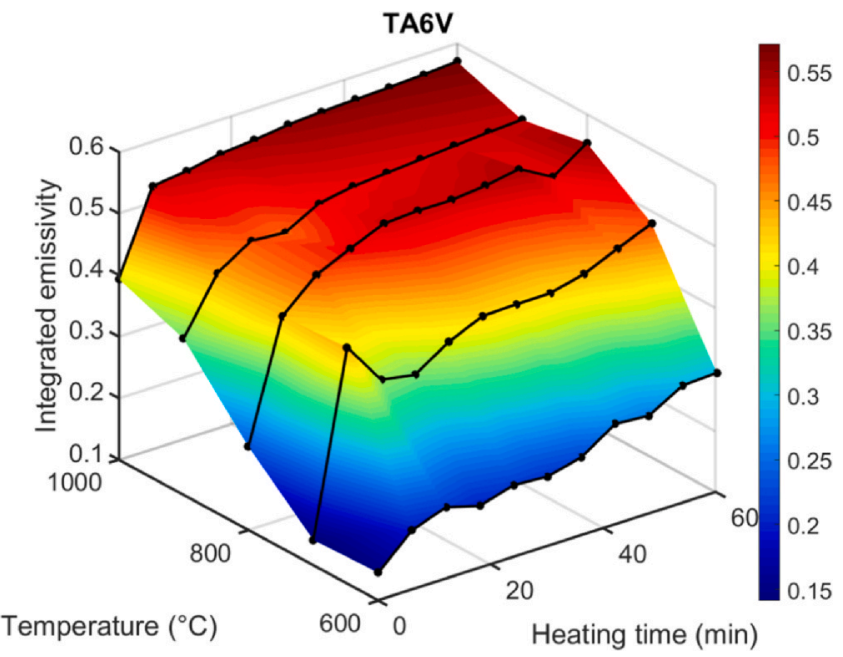

Fig. 13. Integrated emissivity versus heating time and temperature.

shows an increasing emissivity with temperature, in conformity with the decrease of spectral emissivity toward larger wavelengths. Indeed, the more the temperature rises, the more short wavelengths governs the radiation.

At constant temperature, the integrated emissivity is monotonously increasing, in conformity with kinetic oxidation laws,

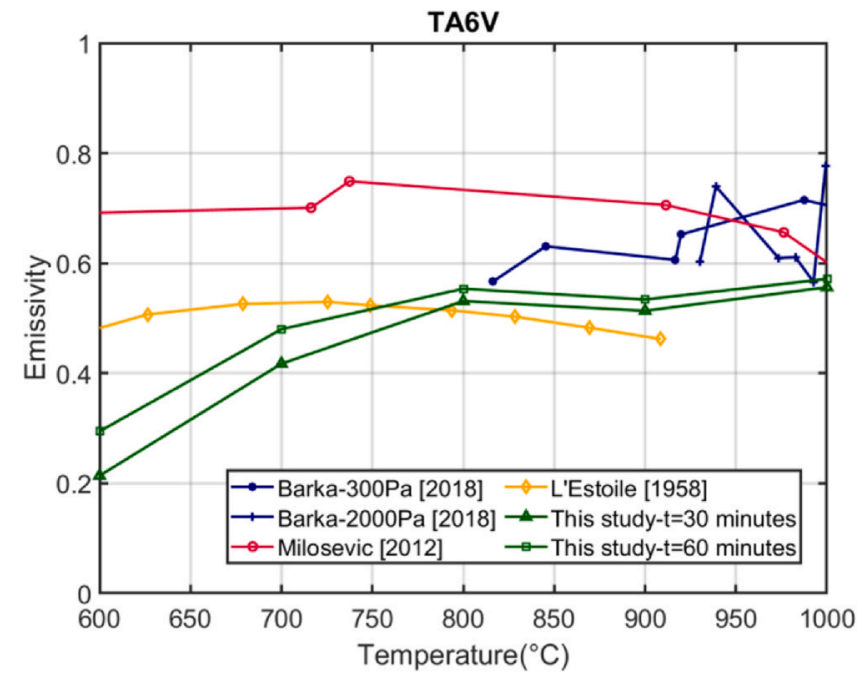

Fig. 14. integrated emissivity of TA6V compared to literature data.

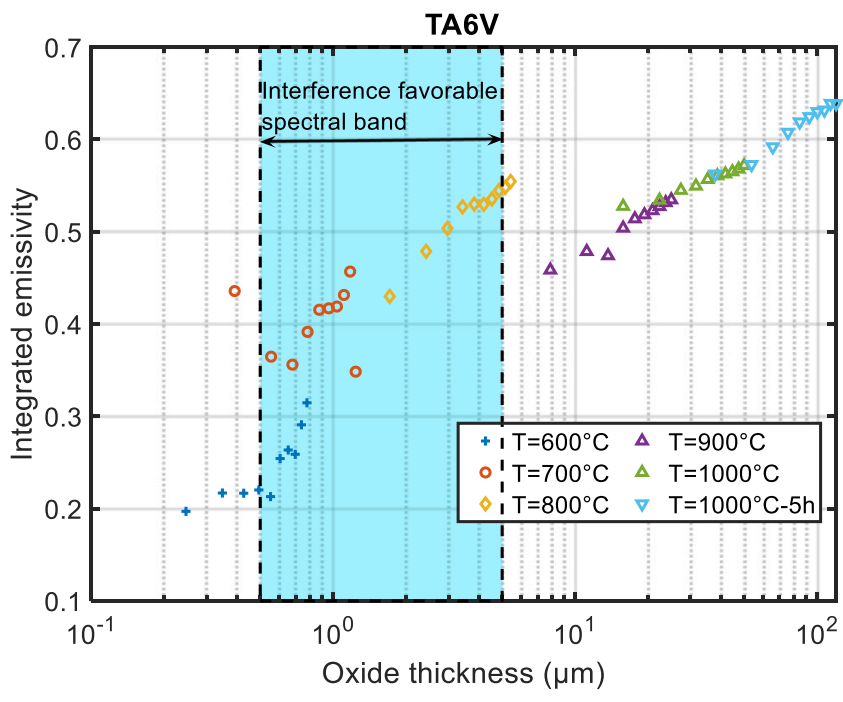

Fig. 15. integrated emissivity versus oxide thickness.

parametrized in Fig. 5. A remarkable point is the connection of the values obtained at $900{ }^{\circ} \mathrm{C}-1 \mathrm{~h}, 1000^{\circ} \mathrm{C}-1 \mathrm{~h}$ and $1000^{\circ} \mathrm{C}-5 \mathrm{~h}$. Their trend is the same as the one obtained for $600{ }^{\circ} \mathrm{C}-1 \mathrm{~h}$, even if the oxide nature is different (rutile $\rightarrow$ alumina). This promotes the repeatability and accuracy of the measurement, and shows great potentiality for the in-situ optical control of oxide thickness. Those patterns are consistent with XRD measurements performed in part 3.4. In conclusion, emissivity shows a strong dependence to both oxide thickness and oxide layer composition.

\section{Conclusion}

The purpose of this work was to link optical properties of an emblematic alloy of aeronautics industry TA6V to its oxide layer thickness and nature. To do so, an emissivity measurement device developed in previous works was used. 6 thermal cycles were chosen: from $600^{\circ}$ to $1000^{\circ} \mathrm{C}$ with a step of $100^{\circ} \mathrm{C}$, and another longer thermal cycle at $1000^{\circ} \mathrm{C}$ with a heating time of $5 \mathrm{~h}$.

First of all, post mortem analysis is performed on the sample. The oxidation law, based on a parabolic trend and Arrhenius law, is parametrized thanks to the measurement of mass gain and oxidation thickness with micro-weighting and SEM. Thanks to this oxidation law, it is then possible to calculate oxide thickness versus heating time, and to infer the domains where thicknesses could induce interference phenomenon. The oxide thickness calculated covered a very wide range from $250 \mathrm{~nm}$ to $150 \mu \mathrm{m}$. XRD characterizations were also done on oxidized samples after heating. Presence of $\mathrm{TiO}_{2}$ was proven for temperature lower than $900{ }^{\circ} \mathrm{C}$, and alumina beyond.

In a second time, both spectral directional and integrated directional emissivity of TA6V alloy are measured between 600 and $1000{ }^{\circ} \mathrm{C}$. Semi-transparency is seen at low temperatures especially at $700{ }^{\circ} \mathrm{C}$ with strong oscillations. The temperature effect on emissivity was particularly significant below $800^{\circ} \mathrm{C}$ while heating time have a strong influence in the first $20 \mathrm{~min}$. Alumina's Christiansen point at $10 \mu \mathrm{m}$ is also identified at high temperatures. Comparison with literature has shown a good agreement for a temperature higher than $700{ }^{\circ} \mathrm{C}$. Discrepancy on emissivity values between sources was the main motivation that led us to link emissivity to oxidation kinetics rather than temperature or heating time.

Oxide thicknesses and emissivity values are then correlated. Semi-transparency effects are noticed for thicknesses between $650 \mathrm{~nm}$ and $5 \mu \mathrm{m}$. Two patterns can be singled out: an oxide mainly composed of $\mathrm{TiO}_{2}$ below $900{ }^{\circ} \mathrm{C}$ while it is composed of both rutile and alumina for temperatures higher or equal to $900{ }^{\circ} \mathrm{C}$. Those 
patterns are consistent with XRD measurements. Those results show the strong dependence of metallic materials emissivity to their oxide layer. Oxide thickness and layer composition have both a strong effect on emissivity value. Heating time which affects alumina proportion in the oxide layer is then especially important on its optical behavior. Knowledge on the oxide layer in addition to temperature seems necessary to whom want to select the right emissivity value (if in-process measurement are made impossible).

The characterization device used in this paper enables measurements for a temperature range sufficient to cover several kinds of hot forming applications. Spectral measurements can be used for temperature measurements (IR pyrometer and thermography) while integrated emissivity can be used in heat transfer computation. Spectral measurements are also useful to have a better assessment of IR radiation/matter interaction in the case of IR heating (dependency to radiative sources characteristics). Moreover, the correlation between oxide thickness and emissivity detailed in this paper offers another way to select the good value given that different samples lead to different oxidation kinetics and emissivity values. Knowing the oxide layer composition and its thickness will then make possible to select the right emissivity value. This device can extend emissivity data for several alloys at high temperature depending on different parameters (temperature, heating time, oxide thickness).

Several possibilities are open to further develop this oxidation/ emissivity link field. One of them is to study longer heating time in order to have a higher alumina proportion for temperatures lower than $900^{\circ} \mathrm{C}$. The influence of a coating like Boron Nitride used as lubricant on oxide/emissivity interaction is also a promising prospect. At larger scales, this set-up is able to provide easily different kind of thermal cycles that can be close to real industrial thermal cycles and to provide a better understanding of radiation heat exchange in thermomechanical processes.

\section{CRediT authorship contribution statement}

A. El Bakali: Data curation, Formal analysis, Validation, Investigation, Writing - review \& editing. R. Gilblas: Conceptualization, Methodology, Validation, Investigation, Writing review \& editing, Supervision. T. Pottier: Data curation; Formal analysis, Writing - review \& editing, Supervision. A. Lieurey: Resources, Investigation. Y. Le Maoult: Project administration, Supervision, Writing - review \& editing.

\section{Declaration of Competing Interest}

The authors declare that they have no known competing financial interests or personal relationships that could have appeared to influence the work reported in this paper.

\section{Acknowledgements}

The team would like to thank Karim Choquet for his work on XRD diffractometry.

\section{References}

[1] Y.S. Yeram, S. Touloukian, Thermophysical Properties of Matter; [The TPRC Data Series; A Comprehensive Compilation of Data], Purdue University. Thermophysical Properties Research Center, 1970.

[2] V.V.K. Prasad Rambabu, N. Eswara Prasad, R.J.H. Wanhill, Aerospace Materials and Material Technologies, Volume 1: Aerospace Material Technologies, Aerosp. Mater. Mater. Technol. 1 (2017) 586.

[3] P.R. Wedden, F. Liard, Design and Development Support for Critical Helicopter Applications in Ti-6A1-4V Alloy, Titanium Science and Technology, Springer US,, 1973, pp. 69-80.

[4] C. Sanz, et al., Micro-scale finishing of the surface and form of a Ti-6Al-4V lightweight rotor obtained by laser powder bed fusion used for air bearing, Addit. Manuf. 23 (2018) 287-293.
[5] P.J. Golden, Development of a dovetail fretting fatigue fixture for turbine engine materials, Int. J. Fatigue 31 (4) (2009) 620-628.

[6] A. Colin, C. Desrayaud, M. Mineur, F. Montheillet, A physically based flow rule for the simulation of Ti-6Al-4V forging in the $\alpha-\beta$ range, Mater. Sci. Forum 539-543 (2007) 3661-3666.

[7] F. Gao, M. Li, P. Ding, Relationship Between Diameter of Tensile Specimen and Grain Size for TA6V Castings, High Performance Structural Materials, Springer Singapore, Singapore, 2018, pp. 549-555.

[8] B. Chartrel, Analyse et optimisation des procédés de formage de pièces en alliage de Titane, Mines Paris (2016).

[9] D. Mauduit, M. Le Fournier, K. Grondin, T. Pottier, Y. Le-Maoult, Industrial applications of the superplastic forming by using Infra-Red heater, Procedia Eng. 207 (2017) 1898-1903.

[10] Y. Robert, Simulation numérique du soudage du TA6V par laser YAG impulsionnel: caractérisation expérimentale et modélisation des aspects thermomécaniques associés à ce procédé, Mines Paris. (2007).

[11] M. Harzallah, T. Pottier, R. Gilblas, Y. Landon, M. Mousseigne, J. Senatore, A coupled in-situ measurement of temperature and kinematic fields in Ti-6Al-4V serrated chip formation at micro-scale, Int. J. Mach. Tools Manuf. 130-131 (2018) 20-35.

[12] G. Bernhart, J.-P. Arcens, and Y. Le Maoult, Innovative Superplastic Forming Based on In-Situ Infra-Red Sheet Heating, 2013.

[13] M.LE Fournier, F. Nazaret, O. Barrau, E. Lebard, and V. Vidal, The use of infra-red heater in superplastic forming: a way of saving costs, in: Proceedings of the 13th World Conference on Titanium, Hoboken, NJ, USA: John Wiley \& Sons, Inc., 2016, pp. 1571-1576.

[14] J.R. Howell, R. Siegel, M.P. Mengúç, Thermal Radiation Heat Transfer, CRC Press, 2010.

[15] M.F. Modest, Radiative Heat Transfer, Elsevier Science, 2013.

[16] M. Balat-Pichelin, J. Annaloro, L. Barka, J.L. Sans, Behavior of TA6V alloy at high temperature in air plasma conditions: Part 2-thermal diffusivity and emissivity, J. Mater. Eng. Perform. 29 (7) (2020) 4606-4616.

[17] M.V. Diamanti, B. Del Curto, M. Pedeferri, Interference colors of thin oxide layers on titanium, Color Res. Appl. 33 (3) (2008) 221-228.

[18] G. Lutjering and J.C. Williams, Titanium. Berlin, Heidelberg.

[19] E. Dong, W. Yu, Q. Cai, Alpha-case kinetics and high temperature plasticity of Ti6Al-4V alloy oxidized in different phase regions, Procedia Eng. 207 (2017) 2149-2154.

[20] H.L. Du, P.K. Datta, D.B. Lewis, J.S. Burnell-Gray, Air oxidation behaviour of Ti6Al4V alloy between 650 and 850 ${ }^{\circ}$, Corros. Sci. 36 (1994) 631-642.

[21] S. Kumar, T.S.N. Sankara Narayanan, S. Ganesh Sundara Raman, S.K. Seshadri, Thermal oxidation of Ti6Al4V alloy: Microstructural and electrochemical characterization, Mater. Chem. Phys. 119 (1-2) (2010) 337-346.

[22] B. Sefer, Oxidation and Alpha-Case Phenomena in Titanium Alloys used in Aerospace Industry: Ti-6Al-2Sn-4Zr-2Mo and Ti-6Al-4V, Luleå University of Technology,, 2014.

[23] E. Dong, W. Yu, Qingwu Cai, L. Cheng, and J. Shi, High-Temperature Oxidation Kinetics and Behavior of Ti-6Al-4V Alloy, Oxid. Met., 88.

[24] M. Boivineau, C. Cagran, D. Doytier, V. Eyraud, M. Nadal, B. Wilthan, G. Pottlacher, Thermophysical properties of solid and liquid Ti-6Al-4V (TA6V) alloy, Int. J. Thermophys. 27 (2) (2006) 507-529.

[25] D. Basak, R.A. Overfelt, D. Wang, Measurement of specific heat capacity and electrical resistivity of industrial alloys using pulse heating techniques, Int. J. Thermophys. 24 (6) (2003) 1721-1733.

[26] N. Milošević, I. Aleksić, Thermophysical properties of solid phase Ti-6Al-4V alloy over a wide temperature range, Int. J. Mater. Res. 103 (6) (2012) 707-714.

[27] L. González-Fernández, E. Risueño, R.B. Pérez-Sáez, M.J. Tello, Infrared normal spectral emissivity of Ti-6Al-4V alloy in the 500-1150 K temperature range, J. Alloy. Compd. 541 (2012) 144-149.

[28] L. Li, K. Yu, K. Zhang, Y. Liu, Study of Ti-6Al-4V alloy spectral emissivity characteristics during thermal oxidation process, Int. J. Heat. Mass Transf. 101 (. 2016) 699-706.

[29] W. Zhu, D. Shi, Z Zhu, J. Sun, Effect of the surface oxidization and nitridation on the normal spectral emissivity of titanium alloys Ti-6Al-4V at 800-1100 K at a wavelength of $1.5 \mu \mathrm{m}$, Infrared Phys. Technol. 76 (2016) 200-205.

[30] A.S. Pagan, B. Massuti-Ballester, G. Herdrich, and A.S. Pagan, Total and Spectral Emissivities of Demising Aerospace Materials Development of the miniaturized Pulsed Plasma Thruster PETRUS View project Characterisation of Demisable Materials View project Total and Spectral Emissivities of Demising Aerospace Materials, 2016.

[31] S. Sklarew and A.S. Rabensteine, Emittance Studies of Various High Temperature Materials and Coatings, 1963.

[32] H.T. Betz, WADC TR 56-222 (Pt. II), 1957.

[33] B. Massuti-Ballester, A.S. Pagan, and G. Herdrich, Determination of total and spectral emissivity of space-relevant materials, in: Proc. 8th Eur. Symp. Aerothermodyn. Sp. Veh., no. 1, 2015.

[34] L. Barka, Etude de la survivabilité des débris spatiaux en phase de rentrée atmosphérique (oxydation et émissivité).

[35] A. El Bakali, R. Gilblas, T. Pottier, Y. Le Maoult, A fast and versatile method for spectral emissivity measurement at high temperatures, Rev. Sci. Instrum. 90 (11) (2019) 115116.

[36] A. El Bakali, Contribution à l'étude des échanges thermiques aux interfaces pour les procédés de formage à chaud: développement de moyens de mesure de l'émissivité et de la résistance thermique de contact (RTC) à haute température, Ecole des Mines d'Albi-Carmaux,, 2020. 
[37] M. Honner, P. Honnerová, Survey of emissivity measurement by radiometric methods, Appl. Opt. 54 (4) (2015) 669-683.

[38] H. Akima, Hiroshi, A new method of interpolation and smooth curve fitting based on local procedures, J. ACM 17 (4) (1970) 589-602.

[39] S. Deemyad, I.F. Silvera, Temperature dependence of the emissivity of platinum in the IR, Rev. Sci. Instrum. 79 (8) (2008) 086105.

[40] D. De Sousa Meneses, P. Melin, L. del Campo, L. Cosson, P. Echegut, Apparatus for measuring the emittance of materials from far infrared to visible wavelengths in extreme conditions of temperature, Infrared Phys. Technol. 69 (2015) 96-101.

[41] A.S. Khanna, Introduction to High Temperature Oxidation and Corrosion, ASM International, 2002

[42] S. Arrhenius, Über die Reaktionsgeschwindigkeit bei der Inversion von Rohrzucker durch Säuren, Z. Phys. Chem. 4 (1) (1889).
[43] P. Kofstad, High-temperature oxidation of titanium, J. less Common Met. 12 (6) (1967) 449-464.

[44] H. Guleryuz, H. Cimenoglu, Oxidation of Ti-6Al-4V alloy, J. Alloy. Compd. 472 (1-2) (2009) 241-246.

[45] J. Manara, M. Reidinger, S. Korder, M. Arduini-Schuster, J. Fricke, Development and characterization of low-emitting ceramics, Int. J. Thermophys. 28 (5) (.2007) $1628-1645$.

[46] D. Demange, M. Bejet, and B. Dufour, New Methods for Measuring the Thermal Emissivity of Semi-transparent and Opaque Materials, in: Proceedings of the 2006 International Conference on Quantitative InfraRed Thermography, 2006.

[47] O. Rozenbaum, D. De Sousa Meneses, P. Echegut, Texture and porosity effects on the thermal radiative behavior of alumina ceramics, Int. J. Thermophys. 30 (2) (2009) 580-590. 